\title{
Do Activity Levels Increase After Total Hip and Knee Arthroplasty?
}

\author{
Paula Harding D Clin Physio, Anne E. Holland PhD, \\ Clare Delany PhD, Rana S. Hinman PhD
}

Received: 14 August 2013/Accepted: 9 December 2013/Published online: 19 December 2013

(C) The Association of Bone and Joint Surgeons (B) 2013

\begin{abstract}
Background People with osteoarthritis (OA) often are physically inactive. Surgical treatment including total hip arthroplasty or total knee arthroplasty can substantially improve pain, physical function, and quality of life. However, their impact on physical activity levels is less clear.
\end{abstract}

The institution of one or more of the authors has received funding from the National Health and Medical Research Council (AEH, RSH) and the Australian Research Council (RSH) but that funding does not relate to the work in this manuscript. One of the authors received funding from The Alfred Small Projects Research Grant (PH) and The Alfred Physiotherapy Department Research Fellowship (PH). One of the authors receives royalties from the sales of an educational DVD for managing osteoarthritis (RSH) and for sales of the Asics Gel Melbourne OA shoe (RSH).

All ICMJE Conflict of Interest Forms for authors and Clinical Orthopaedics and Related Research editors and board members are on file with the publication and can be viewed on request. Clinical Orthopaedics and Related Research neither advocates nor endorses the use of any treatment, drug, or device. Readers are encouraged to always seek additional information, including FDA-approval status, of any drug or device prior to clinical use. Each author certifies that his or her institution approved the human protocol for this investigation, that all investigations were conducted in conformity with ethical principles of research, and that informed consent for participation in the study was obtained.

This research was conducted at The Alfred, Melbourne, Australia.

P. Harding, A. E. Holland

Department of Physiotherapy, The Alfred, Melbourne,

VIC, Australia

P. Harding, C. Delany, R. S. Hinman ( $\square)$

Centre for Health, Exercise and Sports Medicine,

Department of Physiotherapy, The University of Melbourne,

Parkville, VIC 3010, Australia

e-mail: ranash@unimelb.edu.au
Questions/purposes We used accelerometers to measure levels of physical activity pre- and (6 months) postarthroplasty and to examine the proportion of people meeting the American Physical Activity Guidelines.

Methods Sixty-three people with hip or knee OA awaiting arthroplasty were recruited from a major metropolitan hospital. Physical activity was measured using accelerometry before, and 6 months after, surgery. The ActiGraph GT1M (ActiGraph LLC, Fort Walton Beach, FL, USA) was used in this study and is a uniaxial accelerometer contained within a small activity monitor designed to measure human movement through changes in acceleration, which can then be used to estimate physical activity over time. Questionnaires were used to assess patientreported changes in pain, function, quality of life, and physical activity. Complete data sets (including valid physical activity data) for both time points were obtained for 44 participants (70\%). At baseline before arthroplasty, the activity level of patients was, on average, sedentary for $82 \%$ of the time over a 24 -hour period (based on accelerometry) and self-rated as "sometimes participates in mild activities such as walking, limited shopping, and housework" according to the UCLA activity scale.

Results There was no change in objectively measured physical activity after arthroplasty. The majority of participants were sedentary, both before and after arthroplasty,

\author{
A. E. Holland \\ Department of Physiotherapy, La Trobe University, \\ Melbourne, VIC, Australia
}


and did not meet the American Physical Activity Guidelines recommended to promote health. This was despite significant improvements in self-reported measures of pain, function, quality of life, and physical activity after arthroplasty.

Conclusions Despite patient-reported improvements in pain, function, and physical activity after arthroplasty, objectively measured improvements in physical activity may not occur. Clinicians should incorporate strategies for improving physical activity into their management of patients after hip and knee arthroplasty to maximize health status. Future research is needed to explore the factors that impact physical activity levels in people after arthroplasty. Level of Evidence Level IV, therapeutic study. See Guidelines for Authors for a complete description of levels of evidence.

\section{Introduction}

Osteoarthritis (OA) is the leading cause of pain and disability among the older population [30]. The physical impairments associated with OA limit a person's capacity to perform everyday activities and participate in work, social, and recreational activities [1]. Consequently, people with OA are less physically active than those without [21] and most do not meet physical activity guidelines recommended for maintenance of good health [15]. Osteoarthritis is the most common reason for a THA or TKA [5]. The success of THA and TKA in relieving pain and improving function for patients with end-stage OA has been well established [14, 24]. Another important goal of arthroplasty is to increase physical activity [6, 7]; however, this goal is poorly understood and has received relatively little evaluation [4, 9, 12, 44].

Physical inactivity is a significant health problem worldwide [27]. American Physical Activity Guidelines for older adults, including those with chronic conditions, recommend 30 minutes of moderate-intensity exercise at least 5 days a week for optimal health [19, 37]. Currently, there is little literature describing the proportion of people who meet American Physical Activity Guidelines after THA or TKA using objective measures of physical activity and there are no standardized approaches for measurement.

Accelerometers are viewed as the most accurate objective measure of physical activity [18, 33]. Contained within small activity monitors, they measure activity counts (summation of the frequency and intensity of vertical accelerations and decelerations measured during select time intervals), steps taken, and intensity of movement [2]. Recent studies exploring physical activity levels in the arthroplasty population using accelerometers [4, 9, 12, 44] have reported conflicting findings regarding changes in physical activity after arthroplasty. Unfortunately, all but one of these studies measured physical activity over short durations of 24 to 48 hours [9, 12, 44], which is less than the recommended minimum of 3 to 5 days (including a weekend day) required to gain accurate measures of habitual physical activity [42].

The primary aims of this study were to (1) measure changes in physical activity using an accelerometer from preoperatively to 6 months after THA or TKA; and (2) determine the proportion of people meeting the American Physical Activity Guidelines [19] at 6 months after arthroplasty. Our secondary aim was to measure concurrent changes in self-reported pain, physical function, quality of life, and physical activity over this time. We hypothesized that (1) physical activity would increase after arthroplasty but (2) the majority of people would not meet the physical activity guidelines at 6 months despite the expected improvements in self-reported pain, physical function, quality of life, and physical activity.

\section{Patients and Methods}

This study was a prospective case series that recruited participants between March 1 and October 15, 2011, from The Alfred, a major tertiary referral public hospital in Melbourne, Australia.

Inclusion criteria were age between 50 and 80 years (inclusive), a diagnosis of hip or knee OA, and waitlisting for a primary THA or TKA. Participants who were wheelchair-bound, or in high-level care facilities (such as nursing homes), were excluded. Participants with comorbidities that significantly affected their level of physical activity such as a previous stroke and those with English language or cognitive barriers were also excluded. A total of 141 adults waitlisted for an elective THA or TKA attended the preadmission clinic between March and October 2011. Seventy-seven adults met the eligibility criteria (Fig. 1) and 63 people were recruited for the study. Of these, there were six participants who did not undergo surgery as scheduled so 57 participants were included in the analysis of participant characteristics. Seven participants at the preoperative assessment had activity monitor technical problems or did not wear the activity monitor for the required period. Three participants withdrew from the study after their surgery and did not attend the 6-month followup, and a further three patients had technical difficulty with the activity monitor or did not wear the activity monitor for the required time at 6 months postoperatively. Therefore, a total of 44 participants had complete valid preoperative and 6-month postoperative physical activity data sets available for the analyses of change in physical activity. There was a greater proportion of participants in 

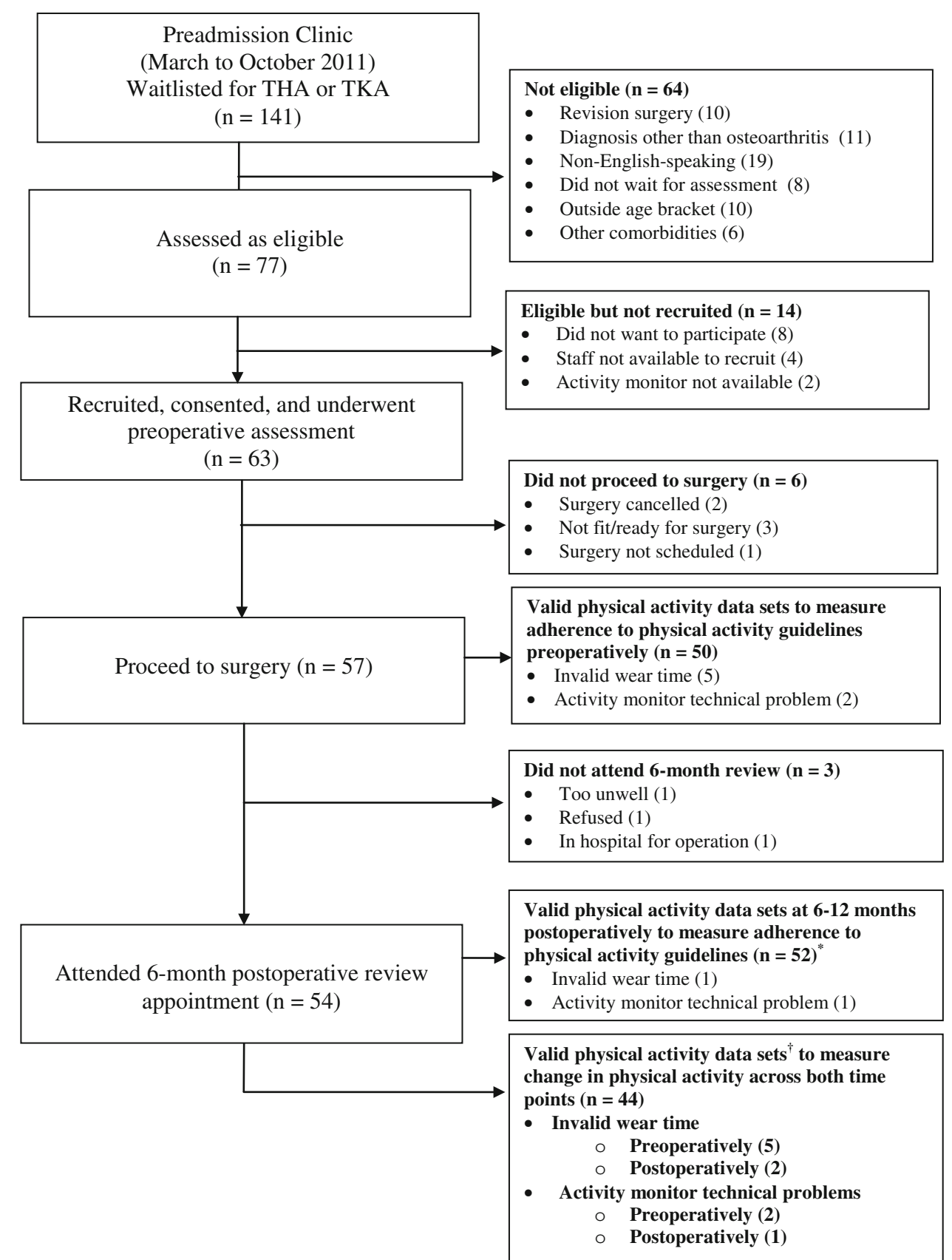

Fig. 1 Flow of participants through the study. * One data set with 3 days of activity monitor data with $<30$ minutes of moderate-intensity physical activity recorded per day was included in the 6-month postoperative data set $(n=52)$ to determine if they met physical activity guidelines (ie, because with the 3 days of data, it could be determined they would not have met the guidelines) but this data set is

the cohort who underwent a TKA (33 [58\%]) compared with THA (24 [42\%]). The 44 patients with valid physical activity data were generally representative of the overall original cohort of 57 patients in terms of demographics, physical parameters, and comorbid conditions (Table 1).

A minimum sample size of 41 provided $80 \%$ power to detect a moderate effect of arthroplasty on physical not included in analysis of change in physical activity $(\mathrm{n}=44)$ between time points because there were not 4 days of valid data; physical activity data recorded by accelerometer for a minimum wear time of 10 hours per day for at least 4 days inclusive of a weekend day at both time points (pre- and postarthroplasty).

activity levels (effect size of 0.45 or mean change in physical activity equivalent to $0.45 \mathrm{SDs}$, which we considered a moderate effect size) with an alpha level of 0.05 .

The median wait time from the preadmission clinic to surgery was 58 days (range, 2-227 days). The type of prosthesis used for surgery was chosen by the individual 
Table 1. Descriptive characteristics of the larger cohort who underwent surgery $(n=57)$ and the cohort with complete valid data sets at both time points $(\mathrm{n}=44)$, presented as mean $(\mathrm{SD})$ or as frequency $(\%)$

\begin{tabular}{|c|c|c|}
\hline Characteristic & $\begin{array}{l}\text { Total } \\
\text { undergoing } \\
\text { surgery } \\
(\mathrm{n}=57)\end{array}$ & $\begin{array}{l}\text { Total with valid } \\
\text { data pre- and } \\
\text { postoperatively } \\
(\mathrm{n}=44)\end{array}$ \\
\hline Age (years) & $69(8.2)$ & $69(8.4)$ \\
\hline \multicolumn{3}{|l|}{ Sex, number $(\%)$} \\
\hline Male & $19(33)$ & $16(36)$ \\
\hline Female & $38(67)$ & $28(64)$ \\
\hline Height (m) & $1.64(0.11)$ & $1.64(0.10)$ \\
\hline Weight (kg) & $84(19)$ & $86(17)$ \\
\hline \multicolumn{3}{|l|}{ Body mass index $\left(\mathrm{kg} / \mathrm{m}^{2}\right)$} \\
\hline Surgery, number (\%) & $31(5.8)$ & $32(5.5)$ \\
\hline THA & 24 & 19 \\
\hline TKA & 33 & 25 \\
\hline \multicolumn{3}{|l|}{ Comorbidities, number (\%) } \\
\hline Cardiovascular & $35(61)$ & $27(61)$ \\
\hline Diabetes & $14(25)$ & $9(21)$ \\
\hline Respiratory & $7(12)$ & $5(11)$ \\
\hline Musculoskeletal* & $19(33)$ & $14(32)$ \\
\hline Other $^{\dagger}$ & $29(51)$ & $20(46)$ \\
\hline Number of comorbidities (\%) & $2.6(1.8)$ & $2.5(1.8)$ \\
\hline \multicolumn{3}{|c|}{ Living situation preoperatively, number (\%) } \\
\hline Home alone & $15(26)$ & $7(16)$ \\
\hline Lives with family & $40(70)$ & $36(82)$ \\
\hline Lives with others & $2(4)$ & $1(2)$ \\
\hline Length of stay (days) & $6.5(4.1)$ & $6.4(4.4)$ \\
\hline \multicolumn{3}{|l|}{$\begin{array}{l}\text { Postoperative destination, } \\
\text { number }(\%)\end{array}$} \\
\hline Inpatient rehabilitation & $22(39)$ & $14(32)$ \\
\hline Home with services & $35(61)$ & $30(68)$ \\
\hline \multicolumn{3}{|l|}{$\begin{array}{l}\text { Adverse events, } \\
\text { number }(\%)\end{array}$} \\
\hline $\mathrm{a}$ & 0 & 0 \\
\hline $\mathrm{b}$ & $6(11)$ & $5(11)$ \\
\hline $\mathrm{c}$ & $13(23)$ & $11(25)$ \\
\hline $\mathrm{d}$ & $8(14)$ & $8(18)$ \\
\hline $\mathrm{e}$ & $1(2)$ & $1(2)$ \\
\hline f & $10(18)$ & $7(16)$ \\
\hline
\end{tabular}

* Musculoskeletal is excluding joint operated on; ${ }^{\dagger}$ other comorbidities included: depression, ovarian cancer, lung cancer, prostate cancer, epilepsy, diverticulitis, hepatitis, Meniere's disease, lymphoma, ulcers, gastroesophageal reflux disease; ${ }^{*}$ adverse events: $\mathrm{a}=$ death related to the original procedure, $\mathrm{b}=$ perioperative complications (medical or surgical), $\mathrm{c}=$ postoperative complications (medical or surgical) that resulted in a delay in discharge, $\mathrm{d}=$ suture line complications (necrosis, haematoma, dehiscence), $\mathrm{e}=$ wound or joint infection, $\mathrm{f}=$ unplanned procedures and/or readmissions during the first 6 months.

orthopaedic consultant but was limited to the prostheses routinely kept in stock. During the study period, prostheses routinely used for THA were either the Corail $\mathbb{R}$ Total Hip
System (DePuy Orthopaedics Inc, Warsaw, IN, USA) (for uncemented THA) or the Exeter Hip (Stryker Orthopaedics, Mahwah, NJ, USA) (for cemented THA). A Pinnacle

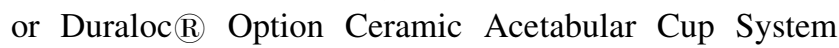
(DePuy Orthopaedics Inc) was available for the acetabulum component. The GENESIS ${ }^{\mathrm{TM}}$ II (Smith \& Nephew Inc,

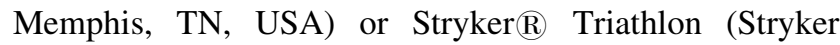
Orthopaedics) prosthesis was used for all TKAs. All participants, regardless of prosthesis received, were managed with the same postoperative protocol and were permitted to weightbear as tolerated. During the inpatient postoperative phase, all participants received standardized routine postoperative care that includes daily physiotherapy. Daily physiotherapy included the physiotherapist assisting participants to mobilize with a gait aid on Day 1 postoperatively and providing them with a bed exercise program. Thirty-five of the $57(61 \%)$ participants were discharged home with ongoing outpatient physiotherapy provided by community services. The remaining participants were discharged to inpatient rehabilitation centers local to where the participant lived and consequently the details of the rehabilitation programs they received are unknown.

Preoperative data were collected at the preadmission clinic by an allied health assistant. Followup data were collected at the routine 6-month postoperative review appointment by an orthopaedic outpatient physiotherapist. Participant information pertaining to age, sex, comorbidities, height, weight, and body mass index (BMI) was extracted from the anesthetic assessment conducted at the preadmission clinic and recorded in the medical history. Comorbidities were categorized as cardiovascular, diabetes, respiratory, musculoskeletal (excluding the affected hip or knee), or other [13]. Because participants could have more than one comorbidity in each category, the total number of comorbidities was also recorded. At the 6-month postoperative review, information from the medical file regarding length of hospital stay, adverse events, and discharge destination was extracted. Adverse events were classified according to the system used in a previously published study [13] and included (1) death relating to the procedure; (2) perioperative complications; (3) postoperative complications resulting in discharge delay; and/or (4) suture line problems, eg, hematoma, dehiscence, wound necrosis, or wound or joint infection as per the definition of Surgical Site Infection from the Centers for Disease Control and Prevention [22].

The primary outcome of interest was physical activity, measured using the ActiGraph $\AA$ GT1M activity monitor (ActiGraph LLC, Fort Walton Beach, FL, USA). It contains a uniaxial accelerometer and is a small, lightweight device worn around the waist under or over clothes [40]. Participants were provided with the activity monitor, detailed verbal and written instructions regarding its use, 
and an activity diary to record times when and why the activity monitor was not worn. Activity monitors were initialized as per the manufacturer's manual [2]. The epoch (the summation of the frequency and intensity of accelerations and decelerations measured during the select time intervals) was set at 1 minute (60 seconds). Participants were instructed to attach the activity monitor as close as possible to the body's center of mass [42] using an elasticized belt around their waist and to wear it for a minimum of 10 hours, during waking hours, for 7 consecutive days. Participants were telephoned in the days after the issue of the activity monitor to encourage compliance. If participants had forgotten to wear the activity monitor, they were encouraged to wear it for an extra day. Participants were instructed to remove the activity monitor only for waterbased activities such as bathing and swimming. Data from activity monitors were downloaded to a computer with ActiGraph software installed. The minimum requirement for nonzero epochs within an hour was set at 5\%. Therefore, for hourly activity data to be valid, a minimum of 3 minutes of nonzero epochs per hour had to be recorded. Furthermore, for a data set to be valid, the activity monitor had to be worn for at least 10 hours for a minimum of 4 of the 7 days, one of which had to be a weekend day. Weartime calculations using the ActiGraph software were performed only on valid data sets.

Amount of activity was indicated by physical activity counts, which were averaged over time and reported as counts per minute (cpm). Two different methods of calculation were used (Table 2). Method 1 provided the average activity counts during valid wear time only and therefore did not include the time when the activity monitor was not being worn. In comparison, Method 2 included nonwear time (such as overnight and when the monitor was not being worn) on valid days and assumed all nonwear time was nonactive time. Intensity of activity was evaluated by categorizing activity as [2, 17]: (1) sedentary < $100 \mathrm{cpm}$; (2) light 100 to $1953 \mathrm{cpm}$; (3) moderate 1954 to $5724 \mathrm{cpm}$; or (4) vigorous $>5725 \mathrm{cpm}$. The cut point ranges recommended in the ActiGraph software manual were calculated from calibration studies and correspond to physical activity expressed as the standard unit of metabolic equivalent (MET). For example, the moderateintensity cut point range 1954 to $5724 \mathrm{cpm}$ is equivalent to 3 to 5.99 METs. Moderate-intensity activities for which MET has been calculated include: walking the dog (3 METs), vacuuming (3.5 METs), and raking the lawn (4 METs) [3]. For each participant, the percentage of time spent in sedentary activity was extracted directly from the ActiGraph data (Table 2). To determine whether a participant met the minimum levels of physical activity recommended for maintenance of good health, time spent participating in water activities (as reported by the activity diary) per day was added to the participant's raw data set from the activity
Table 2. Variables of interest extracted from activity monitor data

\begin{tabular}{|c|c|}
\hline Variable & Definition/calculation \\
\hline \multicolumn{2}{|l|}{ Method 1 (wear time activity only) } \\
\hline Number of valid days & $\begin{array}{l}\text { Extracted from ActiGraph wear } \\
\text { time validation information }\end{array}$ \\
\hline Total valid wear time hours & $\begin{array}{l}\text { Sum of valid wear time hours } \\
\text { calculated for valid days } \\
\text { extracted from ActiGraph wear } \\
\text { time validation information }\end{array}$ \\
\hline Total activity counts & $\begin{array}{l}\text { Extracted from ActiGraph cut point } \\
\text { breakdown information (valid } \\
\text { time only) }\end{array}$ \\
\hline Average counts per day & $\begin{array}{l}\text { Total activity counts divided by } \\
\text { number of valid days }\end{array}$ \\
\hline Average counts per hours & $\begin{array}{l}\text { Average counts per day divided by } \\
\text { total valid wear time hours }\end{array}$ \\
\hline Average counts per minutes & $\begin{array}{l}\text { Average counts per hour divided by } \\
60 \text { (to convert to minutes) }\end{array}$ \\
\hline \multicolumn{2}{|c|}{ Method 2 (total activity $=$ nonwear time and wear time) } \\
\hline Average counts per minute & $\begin{array}{l}\text { Extracted directly from ActiGraph } \\
\text { cut point breakdown information } \\
\text { (calculated by ActiGraph } \\
\text { software as total activity counts } \\
\text { divided by sum of total time } \\
\text { measured over valid days) }\end{array}$ \\
\hline $\begin{array}{l}\text { Percent of total time measured } \\
\text { spent in sedentary intensity* }\end{array}$ & Extracted directly from ActiGraph \\
\hline
\end{tabular}

* Sedentary intensity is defined as $<100$ activity counts per minute [44].

monitor. If a minimum of 30 minutes of at least moderateintensity activity per day was recorded for a minimum of 5 days, then the participant was categorized as having met the American Physical Activity Guidelines [19]. The American Physical Activity Guidelines was chosen as the criterion for measuring physical activity because it describes the amount and intensity of physical activity recommended for older adults, including adults with disabilities and chronic conditions such as those with OA.

Participants wore the physical activity monitor preoperatively for an average of 14 hours per day for 6.52 days and for an average of 14 hours per day for 6.86 days at 6 months after arthroplasty.

Secondary outcome measures included the following self-reported questionnaires: numerical pain rating scale (11-point scale ranging from 0 to 10) during activity and at rest [8, 39]; Oxford Hip and Knee Score (12-item scale measuring pain and physical function) [10, 11]; SF-12 Generic Health Survey (generic quality-of-life measure with two components-a physical component summary and a mental component summary [MCS]) [29, 41, 45]; University of California Los Angeles (UCLA) activity score (with 10 descriptive activity levels ranging from wholly inactive and dependent on others [level one], sometimes 
participates in moderate activities such as swimming, unlimited housework, or shopping [level 5], to regular participation in impact sports [level 10]) [34, 48]; and a patient-reported global rating of change (GRC) score for measuring self-perceived change in physical activity (measured postoperatively using a 7-point Likert scale ranging from very much worse to very much better) [16, 23].

Data were analyzed using SPSS Statistics (Version 19; SPSS Inc, Chicago, IL, USA). Before statistical analyses, data were assessed for normality using the KolmogorovSmirnov test. Because most data were not normally distributed, nonparametric tests were performed for statistical analyses related to study hypotheses. Median and interquartile range were calculated for descriptive purposes and Wilcoxon signed-rank tests were used to continuous compare data across time points. Statistical analyses were conducted within the entire cohort as well as separately within the subgroups of people undergoing either THA or TKA. Probability values $<0.05$ were considered statistically significant.

\section{Results}

There was no change in objectively measured physical activity over time (Table 3 ) either in the entire cohort or within the subgroups of THA and TKA participants using the physical activity monitor. There was also no change in activity intensity after arthroplasty. Preoperatively, participants spent $82 \%$ (interquartile range [IQR], 7.8) of the time measured engaged in sedentary activities compared with $83 \%$ (IQR, 8.2) at 6 months postoperatively ( $\mathrm{p}=0.11)$.

Very few patients met the American Physical Activity Guidelines either before or after recovery from arthroplasty. Of the 57 participants enrolled in the study, 50 participants $(88 \%)$ had physical activity data (accelerometer data plus activity diary) available preoperatively to determine the proportion meeting the American Physical Activity Guidelines [19]. Of these participants, only three (6\%) met the American Physical Activity Guidelines. At 6 months postoperatively, 52 participants $(91 \%)$ had data available. Only one participant (2\%), who underwent THA, met the American Physical Activity Guidelines.

Although there were no significant objective increases in activity, we noted with interest that most patients reported not just improvement in pain after surgery, but also a subjective increase in function. In the cohort of 44 participants with valid accelerometer data sets at both time points, there were significant improvements in self-reported pain during activity $(\mathrm{p}<0.001)$, physical function $(\mathrm{p}<$ $0.001)$, quality of life ( $\mathrm{p}<0.001)$, and in physical activity measured by the UCLA activity score $(\mathrm{p}<0.001)$ after arthroplasty (Table 4). When the groups of THAs and TKAs were analyzed separately, similar results were obtained with the exception of quality of life (MCS). Most participants $(n=31$ [72\%]) reported improvement in physical activity on the GRC score (categorized as those reporting either very much or much improved) (Fig. 2).

\section{Discussion}

Although lower extremity arthroplasty is known to decrease patients' pain and improve function and quality of life, objective studies documenting increased physical activity (one possible measure of improved function) are few [14, 43]. This study aimed to measure physical activity using accelerometers preoperatively and at 6 months after arthroplasty and to describe the proportion of people meeting physical activity guidelines by this time. Our results show that arthroplasty did not influence physical activity at 6 months postoperatively and people did not meet physical activity guidelines despite selfreported improvements in all self-reported secondary outcome measures of pain, physical function, quality of life, and physical activity (other than pain at rest).

There are a few limitations to consider with this study. We used a sample of convenience and the sample was small for the main comparative analysis across time points. Valid physical activity data were unavailable for some participants and several people did not undergo surgery as planned. However, the patients in whom we did not have complete data were in nearly all measurable respects similar to those in whom we did have complete data (Table 1). We observed no difference in physical activity over time, but it is possible this might be because the study was underpowered. We were powered to detect a change in physical activity over time of 0.45 SDs (which we considered a moderate effect size). Thus, smaller changes in physical activity may have existed but may not have been detected in our sample. Although a larger sample may have shown statistically significant differences, the mean change in physical activity was an increase of $12 \mathrm{cpm}$ (using Method 1) and it is unlikely that this is a clinically relevant increase considering less than $100 \mathrm{cpm}$ is considered sedentary (resting) activity. The proportion of time spent in sedentary activity was $82 \%$ preoperatively and this only increased to $83 \%$ postoperatively. A further limitation is waist-mounted uniaxial accelerometers have been reported to underestimate activities such as cycling [32]; however, data from UCLA activity scores and activity diaries indicate most of this cohort did not participate in activities like cycling. A well-documented limitation with use of accelerometers relates to different values of activity count cut points to determine moderate-intensity physical activity [17, 28, 31]. The cut points we used in this study were recommended in the ActiGraph manual, but these cut points were based on equations 
Table 3. Amount of physical activity and proportion of sedentary activity recorded preoperatively and at 6 months postoperatively, reported as median (interquartile range)

\begin{tabular}{|c|c|c|c|c|c|}
\hline Physical activity & & $\begin{array}{l}\text { Number of } \\
\text { participants }\end{array}$ & Preoperatively & $\begin{array}{l}6 \text { months } \\
\text { postoperatively }\end{array}$ & $\mathrm{p}$ value \\
\hline \multirow[t]{6}{*}{ Amount of activity } & \multirow{3}{*}{$\begin{array}{l}\text { Method 1: average accelerometer } \\
\text { activity counts }(\mathrm{cpm})\end{array}$} & Total $(\mathrm{n}=44)$ & $149(133)$ & $161(86)$ & 0.12 \\
\hline & & THA $(\mathrm{n}=19)$ & 125 (107) & $109(166)$ & 0.63 \\
\hline & & TKA $(n=25)$ & $183(143)$ & $159(89)$ & 0.06 \\
\hline & \multirow{3}{*}{$\begin{array}{l}\text { Method 2: Average accelerometer } \\
\text { activity counts }(\mathrm{cpm})\end{array}$} & Total $(n=44)$ & $96(73)$ & $93(72)$ & 0.13 \\
\hline & & THA $(\mathrm{n}=19)$ & $76(74)$ & $63(93)$ & 0.79 \\
\hline & & TKA $(n=25)$ & $104(61)$ & $98(57)$ & 0.07 \\
\hline \multirow[t]{3}{*}{ Intensity of activity } & \multirow{3}{*}{$\begin{array}{l}\text { Proportion of time engaged in } \\
\text { sedentary activity* }(\%)\end{array}$} & Total $(\mathrm{n}=44)$ & $82(7.8)$ & $83(8.2)$ & 0.11 \\
\hline & & THA $(\mathrm{n}=19)$ & $84(9.8)$ & $86(10)$ & 0.33 \\
\hline & & TKA $(\mathrm{n}=25)$ & $82(7.1)$ & $83(7.9)$ & 0.17 \\
\hline
\end{tabular}

* Sedentary intensity is defined as $<100$ activity counts per minute [19,44]. A p value $<0.05$ was considered statistically significant; Method $1=$ activity counts calculated using wear hours only on valid days; Method $2=$ activity counts calculated inclusive of wear hours and nonwear hours on valid days; $\mathrm{cpm}=$ counts per minute.

Table 4. Secondary outcome measures taken at baseline and 6 months after THA or TKA, presented as median (interquartile range) unless indicated (for participants who had complete physical activity data at both baseline and 6 months postoperatively)

\begin{tabular}{llclr}
\hline $\begin{array}{l}\text { Secondary } \\
\text { outcome }\end{array}$ & $\begin{array}{l}\text { Number of } \\
\text { participants }\end{array}$ & $\begin{array}{c}\text { Baseline } \\
\text { postoperatively }\end{array}$ & p value \\
\hline NPRS rest & Total $(\mathrm{n}=44)$ & $3(6)$ & $1(5)$ & 0.06 \\
& THA $(\mathrm{n}=19)$ & $4(5)$ & $1(4)$ & 0.09 \\
& TKA $(\mathrm{n}=25)$ & $2(7)$ & $1(5)$ & 0.25 \\
NPRS & Total $(\mathrm{n}=44)$ & $8(5)$ & $3(5)$ & $<0.001$ \\
activity & THA $(\mathrm{n}=19)$ & $8(5)$ & $2(5)$ & $<0.001$ \\
& TKA $(\mathrm{n}=25)$ & $8(5)$ & $3(5)$ & $<0.001$ \\
Oxford score & Total $(\mathrm{n}=44)$ & $16(9)$ & $35(15)$ & $<0.001$ \\
& THA $(\mathrm{n}=19)$ & $11(11)$ & $35(17)$ & $<0.001$ \\
SF-12 PCS & TKA $(\mathrm{n}=23)$ & $17(8)$ & $34(13)$ & $<0.001$ \\
& Total $(\mathrm{n}=44)$ & $30(9.9)$ & $38(14)$ & $<0.001$ \\
THA $(\mathrm{n}=19)$ & $31(8.7)$ & $34(19)$ & 0.008 \\
SF-12 MCS & TKA $(\mathrm{n}=25)$ & $30(12)$ & $40(11)$ & 0.001 \\
& Total $(\mathrm{n}=44)$ & $40(24)$ & $52(16)$ & $<0.001$ \\
& THA $(\mathrm{n}=19)$ & $37(18)$ & $50(16)$ & 0.001 \\
UCLA & TKA $(\mathrm{n}=25)$ & $44(29)$ & $55(18)$ & 0.078 \\
activity & Total $(\mathrm{n}=43)$ & $3(1)$ & $4(3)$ & $<0.001$ \\
score & THA $(\mathrm{n}=18)$ & $3(1)$ & $4(3)$ & 0.005 \\
& TKA $(\mathrm{n}=25)$ & $3(1)$ & $5(3)$ & $<0.001$ \\
\hline
\end{tabular}

NPRS $=$ Numerical Pain Rating Scale: $0-10$ where $0=$ no pain to $10=$ worst possible pain; UCLA = University of California Los Angeles activity score, a descriptive activity score ranging from $1=$ inactive, sedentary to $10=$ impact sports and heavy labour; $\mathrm{PCS}=$ physical component summary; MCS = mental component summary. A lower SF-12 score indicates poorer physical and/or mental health. Oxford Score is a 12 -item questionnaire score $0-48$ where a score of $48=$ best possible outcome. The Oxford hip score questionnaire provided to patients with THA and the Oxford knee score questionnaire provided to patients with TKA. A p value $<0.05$ was considered statistically significant. developed in the laboratory setting using healthy adult males, which may not necessarily be applicable to our sample of older adults after THA or TKA. Activity cut points have been calibrated using the ActiGraph accelerometer in middle-aged to old obese/overweight and Type 2 diabetes mellitus adult patients [28]. An analysis using these different cut points for moderate-intensity exercise was conducted and the results of the proportion of people meeting the activity guidelines was no different when compared with results using the cut points recommended in the ActiGraph manual. Further research is required to determine the most accurate activity count cut points to use in an arthroplasty population. We chose 6 months postoperatively because the largest improvements in all aspects of physical function and self-reported outcomes after THA or TKA typically occur by this time $[25,26,35,36,43]$. However, longer timeframes may be required for improvements in physical function to translate into increases in physical activity after arthroplasty.

We combined THA and TKA participants into a single group for analysis given our relatively small sample. However, this can be considered a limitation given that recovery after THA has been reported to be greater and occur earlier than after TKA [14], and thus may have influenced the degree of change we observed in the secondary outcomes of pain, physical function, and quality of life. However, for the primary outcome of physical activity, there is evidence to suggest there is no difference between these two groups [6, 12]. Although we performed a subgroup analysis of change in physical activity for THA and TKA participants separately, it is important to note the small samples in each group mean these analyses are underpowered and the findings should be considered hypothesis-generating rather than conclusive. The low percentage of people in this study meeting the physical activity guidelines pre- and 


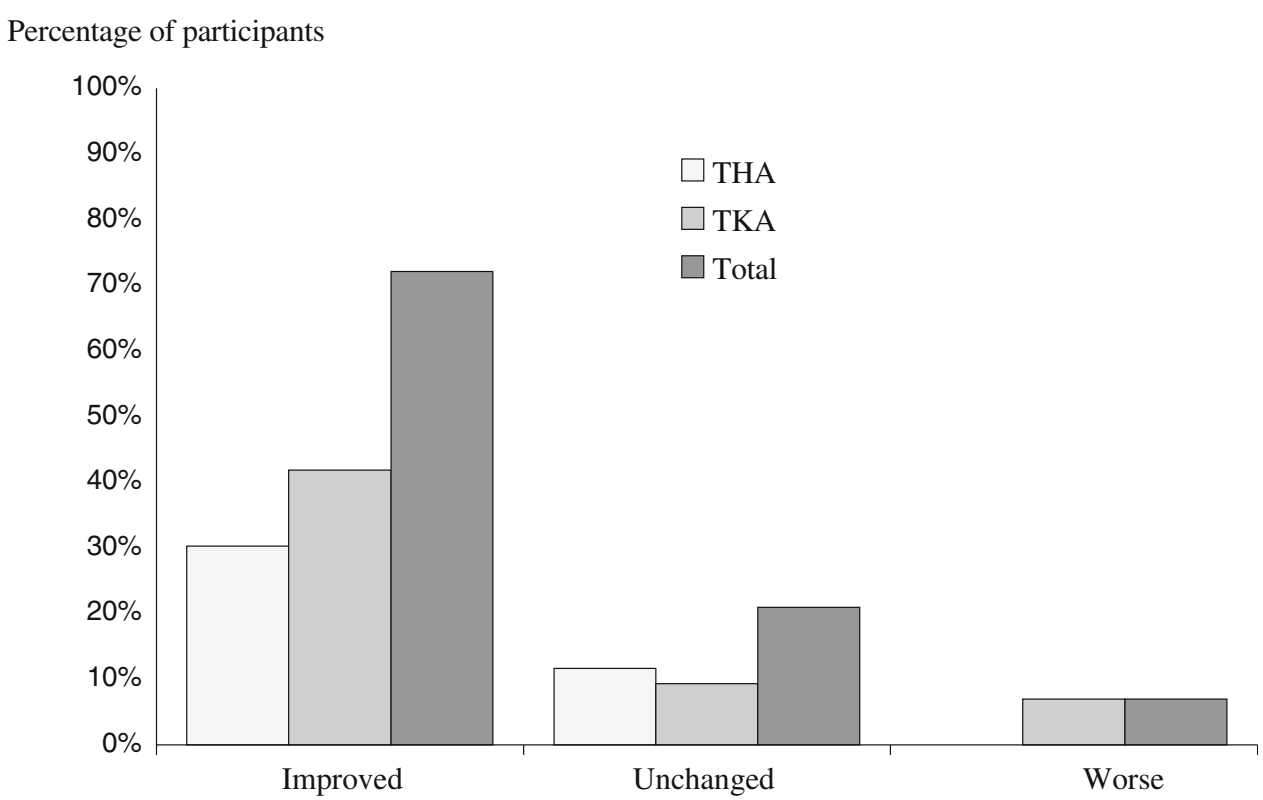

Fig. 2 GRC scale for physical activity: proportion of participants reporting change in physical activity at 6 months postoperatively after THA and TKA $(n=44)$. Improved $=$ GRC categories very much

postoperatively may suggest the use of the physical activity guidelines as a measure is too hard a criterion; however, regular, low-impact physical activity is recommended as a management strategy universally by clinical guidelines for management of patients with OA [38, 49] and the guidelines are written to be inclusive of older adults with chronic conditions. In addition, engaging people to meet the physical activity guidelines is the number one recommendation by the American Academy of Orthopaedic Surgeons for the management of people with knee OA [4]; therefore, we felt it was important to identify if people with OA were able to meet the guidelines. The most common factor influencing physical activity in people with OA is pain [20, 46]. Therefore, it was reasonable to expect physical activity and the proportion of people meeting the physical activity guidelines would increase after surgery that successfully alleviates pain. Hence, the physical activity guidelines provided a clinically relevant benchmark to measure physical activity against pre- and postoperatively.

Four previous studies have measured physical activity using accelerometers before and at 6 months after arthroplasty $[4,9,12,44]$. One of these studies from The Netherlands [12] included a mixed cohort of people after either THA or TKA and in contrast to our study, a significant increase in physical activity at 6 months after THA and TKA was reported. However, this only equated to an increase of 10 minutes of activity per day, which the authors considered to be clinically insignificant. Two of the previous studies, with a cohort of participants after TKA, measured locomotion or ambulation and reported significant increases at 6 months [9, 44]. These improved and much improved grouped together; Unchanged = minimally improved, no change, minimally worse grouped together; Worse $=$ very much worse or much worse grouped together.

different findings compared with our study may be explained by the measurement relating only to ambulation. Ambulation is one component of physical activity. The major difference, however, between these three mentioned studies [9, 12, 44] and our study was the duration of the assessment of physical activity. Our study measured physical activity over 7 days with a minimal requirement of 4 days compared with these three studies that measured physical activity over 24 to 48 hours. This short duration is unlikely to be long enough to capture a reliable estimate of habitual physical activity [42]. Only one of the four previous studies has measured physical activity using accelerometers over 7 days and, consistent with the findings of our study, reported no significant increase in physical activity at 6 months after arthroplasty [4]. That study had a small sample size of 12 females after THA and excluded patients with a BMI $>30 \mathrm{~kg} / \mathrm{m}^{2}$. In contrast, our sample size was larger and the mean BMI for our cohort was $31.1 \mathrm{~kg} / \mathrm{m}^{2}$, which is likely to be more representative of the population with OA who tends to be overweight or obese.

Most people in our study at 6 months after arthroplasty did not meet the American Physical Activity Guidelines. This is an important finding because there is a $20 \%$ to $30 \%$ increased risk of all-cause mortality in people who do not meet physical activity levels specified by physical activity guidelines [47]. This suggests people in our study may be at increased risk of adverse health outcomes. To our knowledge, this is the first study that has used accelerometers to measure the proportion of people meeting physical activity guidelines after THA or TKA. The clinical implications of these findings suggest healthcare professionals need to develop effective strategies 
to help people after arthroplasty translate their increased physical capacity into actual increased physical activity to meet physical activity guidelines and to reduce their risk of adverse health outcomes.

These findings suggest despite people feeling better and more physically capable after arthroplasty, this does not necessarily result in increased physical activity or participation in enough physical activity to promote good health and well-being. Changing physical activity behavior is complex and should not be underestimated by individuals or health professionals, and people with OA considering arthroplasty need to be aware that surgery alone is unlikely to achieve physical activity required for a healthy lifestyle. Further research is required to understand more about the factors such as baseline activity levels, influencing physical activity in people with OA after THA and TKA.

Acknowledgments We thank Associate Professor Sue Liew, Director of Orthopaedic Surgery, The Alfred, for the support and assistance she provided throughout this study. We also thank the participants of this study and staff of The Alfred Orthopedic and Physiotherapy Department who assisted with the recruitment and data collection for this study.

\section{References}

1. 2007 Australian Institute of Health and Welfare. Impairments and Disability Associated With Arthritis and Osteoporosis. Canberra, Australia: Australian Institute of Health and Welfare; 2007.

2. ActiGraph. ActiGraph GT1M Monitor/ActiTrainer and ActiLife Lifestyle Monitor Software User Manual. Fort Walton Beach, FL, USA: ActiGraph; 2007.

3. Ainsworth BE, Haskell WL, Whitt MC, Irwin ML, Swartz AM, Strath SJ, O'Brien WL, Bassett DR Jr, Schmitz KH, Emplaincourt PO, Jacobs DR Jr, Leon AS. Compendium of physical activities: an update of activity codes and MET intensities. Med Sci Sports Exerc. 2000;32:S498-504.

4. American Academy of Orthopaedic Surgeons. Treatment of Osteoarthritis of the Knee: Evidence-based Guideline. 2nd ed. Rosemount, IL, USA: American Academy of Orthopaedic Surgeons; 2013.

5. Australian Orthopaedic Association. Australian National Joint Replacement Registry Annual Report. Adelaide, Australia: Australian Orthopaedic Association; 2011.

6. Bauman S, Williams D, Petruccelli D, Elliott W, de Beer J. Physical activity after total joint replacement: a cross-sectional survey. Clin J Sport Med. 2007;17:104-108.

7. Beaule PE, Dorey FJ, Hoke R, Le Duff M, Amstutz HC. The value of patient activity level in the outcome of total hip arthroplasty. J Arthroplasty. 2006;21:547-552.

8. Bellamy N. Osteoarthritis clinical trials: candidate variables and clinimetric properties. J Rheumatol. 1997;24:768-778.

9. Brandes M, Ringling M, Winter C, Hillmann A, Rosenbaum D. Changes in physical activity and health-related quality of life during the first year after total knee arthroplasty. Arthritis Care Res. 2011;63:328-334.

10. Dawson J, Fitzpatrick R, Murray D, Carr A. Comparison of measures to assess outcomes in total hip replacement surgery. Qual Health Care. 1996;5:81-88.

11. Dawson J, Fitzpatrick R, Murray D, Carr A. The problem of 'noise' in monitoring patient-based outcomes: generic, disease-specific and site-specific instruments for total hip replacement. J Health Serv Res Policy. 1996;1:224-231.

12. de Groot IB, Bussmann HJ, Stam HJ, Verhaar JA. Small increase of actual physical activity 6 months after total hip or knee arthroplasty. Clin Orthop Relat Res. 2008;466:2201-2208.

13. Dowsey MM, Liew D, Stoney JD, Choong PF. The impact of obesity on weight change and outcomes at 12 months in patients undergoing total hip arthroplasty. Med J Aust. 2010;193:17-21.

14. Ethgen O, Bruyere O, Richy F, Dardennes C, Reginster JY. Health-related quality of life in total hip and total knee arthroplasty. A qualitative and systematic review of the literature. J Bone Joint Surg Am. 2004;86:963-974.

15. Farr JN, Going SB, Lohman TG, Rankin L, Kasle S, Cornett M, Cussler E. Physical activity levels in patients with early knee osteoarthritis measured by accelerometry. Arthritis Rheum. 2008;59:1229-1236.

16. Farrar JT, Young JP Jr, LaMoreaux L, Werth JL, Poole RM. Clinical importance of changes in chronic pain intensity measured on an 11-point numerical pain rating scale. Pain. 2001;94:149-158.

17. Freedson PS, Melanson E, Sirard J. Calibration of the Computer Science and Applications, Inc accelerometer. Med Sci Sports Exerc. 1998;30:777-781.

18. Hansen BH, Kolle E, Dyrstad SM, Holme I, Anderssen SA. Accelerometer-determined physical activity in adults and older people. Med Sci Sports Exerc. 2012;44:266-272.

19. Haskell WL, Lee IM, Pate RR, Powell KE, Blair SN, Franklin BA, Macera CA, Heath GW, Thompson PD, Bauman A. Physical activity and public health: updated recommendation for adults from the American College of Sports Medicine and the American Heart Association. Circulation. 2007;116:1081-1093.

20. Hendry M, Williams NH, Markland D, Wilkinson C, Maddison P. Why should we exercise when our knees hurt? A qualitative study of primary care patients with osteoarthritis of the knee. Fam Pract. 2006;23:558-567.

21. Hootman JM, Macera CA, Ham SA, Helmick CG, Sniezek JE. Physical activity levels among the general US adult population and in adults with and without arthritis. Arthritis Rheum. 2003;49:129135.

22. Horan TC, Gaynes RP, Martone WJ, Jarvis WR, Emori TG. CDC definitions of nosocomial surgical site infections, 1992: a modification of CDC definitions of surgical wound infections. Am J Infect Control. 1992;20:271-274.

23. Jaeschke R, Singer J, Guyatt GH. Measurement of health status. Ascertaining the minimal clinically important difference. Control Clin Trials. 1989;10:407-415.

24. Jones CA, Voaklander DC, Johnston DW, Suarez-Almazor ME. Health related quality of life outcomes after total hip and knee arthroplasties in a community based population. J Rheumatol. 2000;27:1745-1752.

25. Kennedy DM, Stratford PW, Hanna SE, Wessel J, Gollish JD. Modeling early recovery of physical function following hip and knee arthroplasty. BMC Musculoskelet Disord. 2006;7:100.

26. Kennedy DM, Stratford PW, Riddle DL, Hanna SE, Gollish JD. Assessing recovery and establishing prognosis following total knee arthroplasty. Phys Ther. 2008;88:22-32.

27. Kohl HW, Craig CL, Lambert EV, Inoue S, Alkandari JR, Leetongin G, Kahlmeier S. The pandemic of physical inactivity: global action for public health. Lancet. 2012;380:294-305.

28. Lopes VP, Magalhaes P, Bragada J, Vasques C. Actigraph calibration in obese/overweight and type 2 diabetes mellitus middle-aged to old adult patients. J Phys Act Health. 2009;6(Suppl 1):S133-140.

29. Luo X, Lynn George M, Kakouras I, Edwards CL, Pietrobon R, Richardson W, Hey L. Reliability, validity, and responsiveness of the Short Form 12-Item Survey (SF-12) in patients with back pain. Spine. 2003;28:1739-1745. 
30. March LM, Bagga H. Epidemiology of osteoarthritis in Australia. Med J Aust. 2004;180:S6-10.

31. Masse LC, Fuemmeler BF, Anderson CB, Matthews CE, Trost SG, Catellier DJ, Treuth M. Accelerometer data reduction: a comparison of four reduction algorithms on select outcome variables. Med Sci Sports Exerc. 2005;37:S544-554.

32. Matthew CE. Calibration of accelerometer output for adults. Med Sci Sports Exerc. 2005;37:S512-522.

33. Naal FD, Impellizzeri FM. How active are patients undergoing total joint arthroplasty?: A systematic review. Clin Orthop Relat Res. 2010;468:1891-1904.

34. Naal FD, Impellizzeri FM, Leunig M. Which is the best activity rating scale for patients undergoing total joint arthroplasty? Clin Orthop Relat Res. 2009;467:958-965.

35. Naylor J, Harmer A, Fransen M, Crosbie J, Innes L. Status of physiotherapy rehabilitation after total knee replacement in Australia. Physiother Res Int. 2006;11:35-47.

36. Naylor JM, Harmer AR, Heard RC, Harris IA. Patterns of recovery following knee and hip replacement in an Australian cohort. Aust Health Rev. 2009;33:124-135.

37. Nelson ME, Rejeski WJ, Blair SN, Duncan PW, Judge JO, King AC, Macera CA, Castaneda-Sceppa C. Physical activity and public health in older adults: recommendation from the American College of Sports Medicine and the American Heart Association. Circulation. 2007;116:1094-1105.

38. Royal Australian College of General Practitioners. Guideline for the Non-surgical Management of Hip and Knee Osteoarthritis South Melbourne, Victoria: Royal Australian College of General Practitioners; 2009.

39. Salaffi F, Stancati A, Silvestri CA, Ciapetti A, Grassi W. Minimal clinically important changes in chronic musculoskeletal pain intensity measured on a numerical rating scale. Eur J Pain. 2004;8:283-291.

40. Silva P, Mota J, Esliger D, Welk G. Technical reliability assessment of the Actigraph GT1M accelerometer. Measurement in Physical Education and Exercise Science. 2010;14:79-91.
41. Sugar CA, Sturm R, Lee TT, Sherbourne CD, Olshen RA, Wells $\mathrm{KB}$, Lenert LA. Empirically defined health states for depression from the SF-12. Health Serv Res. 1998;33:911-928.

42. Trost SG, McIver KL, Pate RR. Conducting accelerometer-based activity assessments in field-based research. Med Sci Sports Exerc. 2005;37:S531-543.

43. Vissers MM, Bussmann JB, Verhaar JAN, Arends LR, Furlan AD, Reijman M. Recovery of physical functioning after total hip arthroplasty: systematic review and meta-analysis of the literature. Phys Ther. 2011;91:615-629.

44. Walker DJ, Heslop PS, Chandler C, Pinder IM. Measured ambulation and self-reported health status following total joint replacement for the osteoarthritic knee. Rheumatology (Oxford). 2002;41:755-758.

45. Ware J Jr, Kosinski M, Keller SD. A 12-Item Short-Form Health Survey: construction of scales and preliminary tests of reliability and validity. Med Care. 1996;34:220-233.

46. Wilcox S, Der Ananian C, Abbott J, Vrazel J, Ramsey C, Sharpe PA, Brady T. Perceived exercise barriers, enablers, and benefits among exercising and nonexercising adults with arthritis: results from a qualitative study. Arthritis Rheum. 2006;55:616-627.

47. World Health Organisation. Global Recommendations on Physical Activity for Health. Geneva, Switzerland: World Health Organisation; 2010.

48. Zahiri CA, Schmalzried TP, Szuszczewicz ES, Amstutz HC. Assessing activity in joint replacement patients. J Arthroplasty. 1998;13:890-895.

49. Zhang W, Nuki G, Moskowitz RW, Abramson S, Altman RD, Arden NK, Bierma-Zeinstra S, Brandt KD, Croft P, Doherty M, Dougados M, Hochberg M, Hunter DJ, Kwoh K, Lohmander LS, Tugwell P. OARSI recommendations for the management of hip and knee osteoarthritis: part III: changes in evidence following systematic cumulative update of research published through January 2009. Osteoarthritis Cartilage. 2010;18:476-499. 